\title{
AEROMAGNETIC MAP OF THE EAST BROOKFIELD QUADRANGLE WORCESTER COUNTY, MASSACHUSETTS
}

GEOPHYSICAL INVESTIGATIONS

MAP GP-621

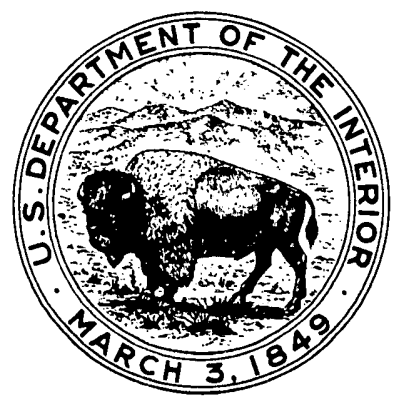

PUBLISHED BY THE U. S. GEOLOGICAL SURVEY WASHINGTON, D.C. 